\title{
Technological approaches to the vinification of Dornfelder grape variety cultivated in Romania
}

\author{
Arina Oana Antoce a and George Adrian Cojocaru \\ University of Agronomic Sciences and Veterinary Medicine of Bucharest, Faculty of Horticulture, Department of \\ Bioengineering of Horti-Viticultural Systems, 59 Marasti Ave., Sector 1, 011464 Bucharest, Romania
}

\begin{abstract}
In Romania, Dornfelder is a rare grape variety which started to become popular among some wine producers due to the intense colour of its wines. However, it is mostly used in blends and therefore varietal wines of Dornfelder are not found too often. In this paper we present some technological approaches suitable for the production of varietal wines of Dornfelder, some of them novel for the Romanian wine industry. The experimental samples include a classical red wine made by the usual technology using freshly harvested grapes (DW = Dornfelder wine) and two variants made with dried grapes (DR and DWDR). The DR variant (Dornfelder raisin wine) is produced by a straw-wine type technology, by fermenting a must obtained from grapes dried for 7 weeks. The DWDR is a variant obtained by fermenting a mixture of crushed dried grapes and new Dornfelder wine, the ratio of crushed raisins to wine being 1:1 in weight. The wines were analysed both physico-chemically and sensorially. After one year of aging in bottles, the variant DWDR of wine, produced by fermenting dried berries in already finished wine, proved to be the most balanced in taste, with an intense and complex aroma of berries and red fruit, also displaying good aging potential and stability. The variant DR appeared dense and intense, but with a less complex fruity aroma, with a dominant note of blueberries and black currants. Both straw wines are preferable to the classic varietal wine, which is vinous, but lacks structure and displays a dissociated acidity and a simple aromatic profile, with dominant sour cherry, mineral and vegetal notes.
\end{abstract}

\section{Introduction}

\subsection{Dornfelder grape variety}

Dornfelder is a black variety used for intensely coloured red wines, very popular in its country of origin, Germany. It was obtained by Harold August in Weinsberg (and called Weinsberg S 341 in 1955) from Helfensteiner (a cross of Frühbrgunder and Trolinger) and Herlodrebe (a cross of Portugieser and Lemberger).

It is protected and registered as Vitis vinifera cross, Vitis vinifera $\mathrm{L}$ cv. Dornfelder. It has $2.93 \mathrm{mg} / \mathrm{g}$ of fresh weight total malvidin derivatives [1], producing wines with content much under the legal limit of $15 \mathrm{mg} / \mathrm{l}$ for malvidin diglucoside [2].

Dornfelder has a high total polyphenol content, Liang and co-workers [1] finding that the value is more than double as compared to that of Cabernet Sauvignon (4.74 mg/g FW in Dornfelder vs. $2.12 \mathrm{mg} / \mathrm{g} \mathrm{FW}$ in Cabernet Sauvignon), this being due to a higher content of both anthocyanins $(4.072 \mathrm{mg} / \mathrm{g} \mathrm{FW}$ in Dornfelder vs. $1.83 \mathrm{mg} / \mathrm{g} \mathrm{FW}$ in Cabernet Sauvignon) and other phenols (flavanols $0.206 \mathrm{mg} / \mathrm{g} \mathrm{FW}$ as compared with $0.138 \mathrm{mg} / \mathrm{g}$ FW in Cabernet Sauvignon, flavonols $0.156 \mathrm{mg} / \mathrm{g}$ FW as compared with $0.039 \mathrm{mg} / \mathrm{g}$ FW in Cabernet Sauvignon).

It is often confused with a teinturier grape variety, due to the red-coloured strains in the pulp of the grapes and the deep colour of the wines.

\footnotetext{
${ }^{a}$ Corresponding author: arina . antoce@horticulturabucuresti.ro
}

The variety has a high yield, particularly on fertile soils. It can easily over-produce and for good quality may need cluster thinning [3]. Due to its large berries, some [1] classify the Dornefelder among table grapes.

Being included in German Federal Office's Varieties Register in 1980, its planting began soon after that and the surfaces with Dornfelder continued to increase ever since. It is mostly cultivated in Germany, 8,197 ha in 2012 [4], mainly in regions of Rheinhessen (3,541 ha in 2012) and Pfalz (3,214 ha in 2012), where $82 \%$ of its total surface is located. In Germany the Dornfelder surfaces represent $8.0 \%$ of the total vine surface $[3,4]$ and $22 \%$ of the total black grape varieties, in both Rheinhessen and Pfalz region occupying $13 \%$ of the total vineyard, respectively [5]. Some other countries have also started to plant it: Austria, Belgium, Bulgaria, Canada, Croatia, United States, Hungary, New Zeeland, Portugal and Switzerland [6] and even Australia and UK.

In Romania the Dornfelder was introduced in the list of the accepted vine varieties in 2011 [6,7], following the recommendation of our university which included it in its collection in 2004 and assessed its performance under the conditions of Southern Romania [8]. As a result, some producers introduced the variety in their plantations, but due to the small surfaces, only one vineyard reported it officially in the vine register and started to produce and put on the market a varietal wine with Controlled Denomination of Origin (eFrame Portal Versiune 1.3, National Vine Register, unavailable to public). 


\subsection{The possible use of Dornfelder grapes for straw wine production in Romania}

As opposed to the traditional regions where Dornfelder is cultivated (European Region B), in Romania we cultivate it in warmer conditions, namely in regions CI and CII.

In Bucharest and in other CII Romanian plantations as well, Dornfelder maturates in the same period with Pinot [9]. Harvested late, it produces highly alcoholic wines, with low acidity, but of very dark colour. The resulted wines, however, give the impression of being less structured, and give a different mouthfeel than that expected from their intense colour. In order to increase the extract, preserve a high content of polyphenols in the wines and increase in this way the aging potential, a technology similar to that for straw wine production could be applied. The wines produced in this way are very sweet and low in acidity, conforming to the preferences of many consumers in Romania.

Straw wines, also called vin de paille or passito wines, are produced in many countries, but in Romania no such wine is commercially available, with the exception of very rare botrityzed Grasa wines from Cotnari or Pietroasa which can be made only in few very favourable years.

Most of the straw wines in the world are white, but a few red passito wines are also known: the Amarone of Valpolicella, produced by a complete fermentation of dried berries (raisins) [10] and Recioto wines, sweet red wines resulting from an incomplete fermentation. In both cases, the grapes used are either botrytized (traditional procedure) or dehydrated in special chambers (modern procedure). In the latter procedure the infection with Botrytis does not occur anymore, any infection being actually highly undesirable.

In Romania, the Dornfelder cannot be vinified in the traditional Amarone style, as the grapes do not develop noble rot. Also, the grapes accumulate so much sugar that a complete fermentation for normally harvested grapes leads to wines exceeding $15 \%(\mathrm{w} / \mathrm{w})$ alcohol. With dehydrated grapes, the alcoholic strength is similar, but the fermentation stops and unfermented sugar inherently remains in the final wine, unlike in Amarone, where remaining sugar does not usually exceed $3 \mathrm{~g} / \mathrm{l}$ [10].
Similarly, in Canada, Dornfelder is sometimes used to make ice-wines. However, here we do not have conditions for the obtainment of natural ice-wines.

\section{Material and methods}

\subsection{Materials}

The grapes used for experiments were harvested on September $19^{\text {th }}, 2013$ from the university experimental vineyard. Under the conditions of Bucharest, Dornfelder maturates well and is ready for harvesting earlier than most of the black grape varieties, in the same period with the Pinot noir [9].

For all the variants the same oenological materials from Enologica Vason [11] were used as follows: Zimared Plus for $12 \mathrm{~h}$ of pre-fermentative maceration, tannin combination Colour Stab (5 g/q) added after the enzymatic maceration for colour stabilisation, Ceppo VP5 wine yeast for fermentation $(30 \mathrm{~g} / \mathrm{q})$. Sulfur dioxide was added as aqueous solution $5 \%$, in doses of $50 \mathrm{mg} / \mathrm{l}$ before fermentation and before bottling.

\subsection{Winemaking}

The winemaking was performed in accordance to the sequences depicted in Fig. 1, using the same batch of grapes.

The control wine (coded DW from Dornfelder Wine) is produced by traditional maceration-fermentation technology, from freshly harvested grapes, fermented to dryness. Then, the rest of the grapes were allowed to dry in a ventilated room at $20^{\circ} \mathrm{C}$ for a period of about 7 weeks, until November $11^{\text {th }}, 2013$. The raisins were crushed and the resulted mash was split, half being fermented as such, while the other half was added to a part of the control wine. The wine resulted from the maceration-fermentation of the crashed raisins was coded DR (Dornfelder Raisins), while the wine resulted from the maceration-fermentation of the DW and crashed raisins, in a 1:1 weight ration, was coded DWDR (Dornfelder Wine with Dornfelder Raisins). These wines produced with raisins (DWDR and DR)

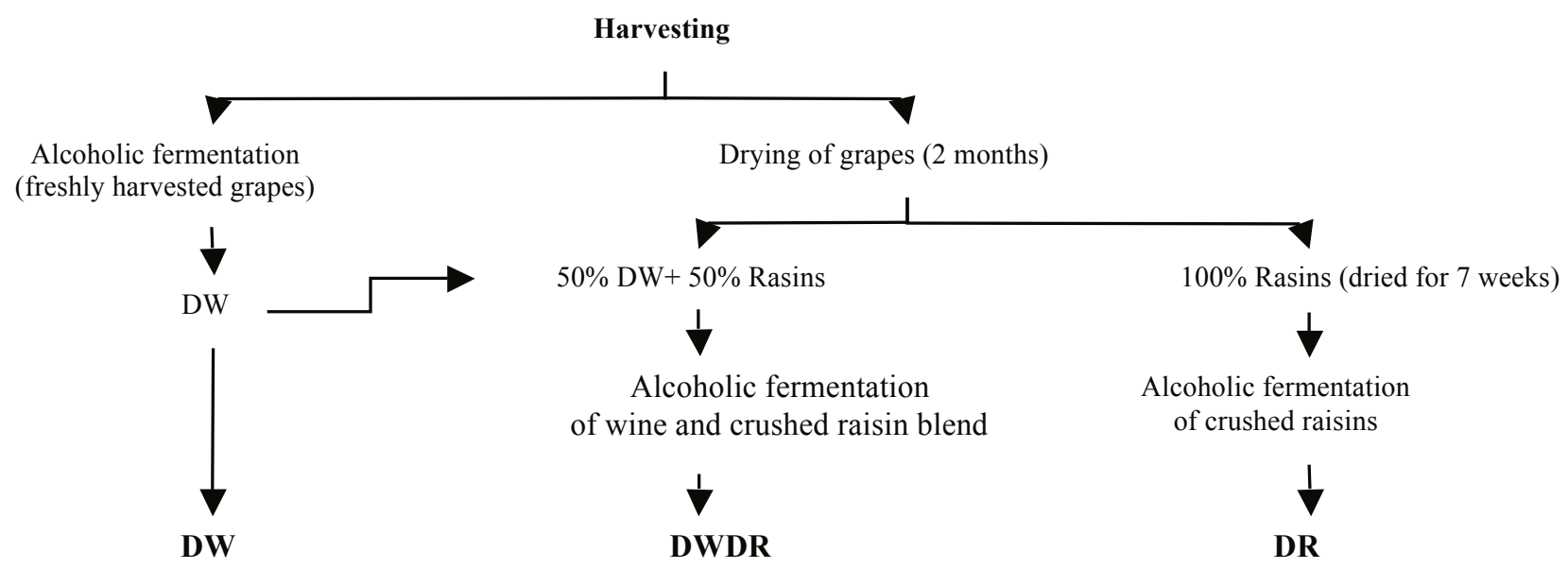

Figure 1. Technological wine variants: DW $=$ Dornfelder Wine (control wine) DWDR $=$ Dornfelder Wine + Dornfelder raisin $(50 \%$ wine $+50 \%$ dried grapes $) ; \mathrm{DR}=$ Dornfelder Raisin $(100 \%$ dried grapes $)$. 
were fermented until the alcoholic fermentation naturally stopped due to high amount of ethanol produced.

The maceration process of the grape mash lasted for 11 days, until the alcoholic fermentation (AF) was completed. Two daily punch-downs were performed manually. Then the wine was separated with a vertical press. No inoculation for malolactic fermentation was performed, this fermentation being unlikely to proceed due to the unfavourable conditions created by the high concentration of ethanol. An amount of 601 of each type of wine was obtained.

One month after, the wines were racked off lees, added with sulphur dioxide and kept in glass demijohns, then 8 months later bottled without further corrections or filtration and used for further analyses. The bottled wines were stored horizontally at $16^{\circ} \mathrm{C}$.

\subsection{Analyses}

The grapes were analyzed both at harvest time and after 7 weeks of natural drying. The uvological analysis of $1 \mathrm{~kg}$ of grapes [12] included berries weight and number, marc weight and numerical ratio of the structural elements of the cluster: rachis, skins, pulp and seeds, while the chemical analyses [13-17] of the resulted musts included sugar content determination by refractometry, density, total acidity, $\mathrm{pH}$, yeast assimilable nitrogen (YAN), total anthocyanins (ApH1), extractable anthocyanins (ApH3.2), total phenols, anthocyanins extractability and seed tannins.

The wines were analysed in triplicates by assessing the standard physico-chemical parameters in accordance to the OIV methods $[13,14]$, including the alcohol content, titratable acidity (TA), volatile acidity (VA), $\mathrm{pH}$, sugar content, total extract and dry extract. The colour-related parameters and polyphenol content were determined by Glorie methodology [15,16], Somers and Evans [17] and OIV methods. Total polyphenol index was measured at $280 \mathrm{~nm}$ in absorbance units, corrected with a factor of 3.9 accounting for non-polyphenol substances absorbing at $280 \mathrm{~nm}$ [18]. All the spectrophotometric determinations were conventionally referred to the optical path of $10 \mathrm{~mm}$ and performed in quartz or glass cuvettes with a UV-VIS double beam spectrophotometer Specord 250 from Analytik Jena AG, running the software WinAspect version 2.2.7.

The data were analysed for differences using T-test and ANOVA functions of Origin 10.0 software.

The wines were also sensorially evaluated after 14 months from bottling by a panel of 5 experienced winetasters, in accordance to the UIO-OIV score sheet for international competitions [19] and also by using a methodology designed in our laboratory and patented at the Romanian Office of Inventions and Trademarks [20]. The score sheet included continuous 0-10 point scales for acidity, sweetness, astringency, extract, colour intensity and total aroma intensity, along with a 5 points discontinuous scale (values normalized at 10) for specific attributes, mainly related to aroma. For the descriptive analysis part of the tasting sheet, no descriptive attributes were provided to the panelists, but were established by consensus. A wine profile was derived by using the average scores obtained for these parameters.
Wine bottles for the sensory analyses were randomly selected from the replicates of each type of wine. The wines were presented in triplicate, in a randomized complete block design. Standard $100 \mathrm{ml}$ OIV glasses were used, each being filled with $50 \mathrm{ml}$ wine. Water and bread were provided as palate cleansers between sample tastings.

\section{Results and discussions}

\subsection{Grape uvological parameters}

The uvological analysis of the fresh and dried grapes are presented in Table 1. As expected, with drying, the ratio of the skin, seeds and the resulted marc relatively increased, as the must obtained from one $\mathrm{kg}$ of grapes decreased. The average weight of the fresh berry is $2.26 \mathrm{~g}$, very close to the value of $2 \mathrm{~g}$ found by Liang et al. [1], suggesting that the berry is medium sized and in the range of the wine grape berry sizes. After 7 weeks of drying the berries shrunk by about $50 \%$, the average weight of a berry being $1.22 \mathrm{~g}$.

\subsection{Must and wine chemical parameters}

The physico-chemical analyses of the musts obtained from fresh grapes in the harvesting day and from grapes naturally dried for 7 weeks (Table 2) showed an expected increase in the sugar content by $35 \%$. The increase in acidity was not important, as the value in fresh grapes was rather low (4.24 $\mathrm{g} / 1$ tartaric acid). However, the yeast assimilable nitrogen displayed a more than 4 times increase. Total anthocyanins, extractable anthocyanins and total phenols increased by $23-33 \%$ with drying, while the anthocyanins extractability improved by $8 \%$. Seed tannins is the only parameter which decreased during the natural drying of grapes, by about $59 \%$, meaning that the increase of the total phenols was mainly based on the skin tannins, which are generally more supple and velvety, as compared to the seed ones, mostly judged as harsh and aggressive.

The wines were also analysed and significant differences were recorded among the variants. The main wine

Table 1. Uvological analysis of $1 \mathrm{~kg}$ of Dornfelder grapes at harvest time and after 7 weeks of natural drying.

\begin{tabular}{|l|l|l|l|l|}
\hline \multirow{2}{*}{$\begin{array}{c}\text { Uvological } \\
\text { components }\end{array}$} & \multicolumn{2}{|c|}{$\begin{array}{c}\text { Fresh grapes (day } \\
\text { of harvesting, } \\
\mathbf{1 9 . 0 9 . 2 0 1 3 )}\end{array}$} & \multicolumn{2}{l|}{\begin{tabular}{l}
\multicolumn{2}{l|}{ Raisins (7 weeks after } \\
harvesting, 11.11.2013)
\end{tabular}} \\
\cline { 2 - 5 } g/kg & \% & g/kg & \% \\
\hline Skins & 163.24 & 16.32 & 204.10 & 20.41 \\
\hline Seeds & 26.61 & 2.66 & 34.40 & 3.44 \\
\hline Rachis & 29.41 & 2.94 & 25.43 & 2.54 \\
\hline Must & 780.75 & 78.07 & 736.12 & 73.61 \\
\hline Grapes, g & $\mathbf{1 0 0 0 . 0 0}$ & $\mathbf{1 0 0 . 0 0}$ & $\mathbf{1 0 0 0 . 0 0}$ & $\mathbf{1 0 0 . 0 0}$ \\
\hline Berries, g/kg & 970.59 & - & 974.62 & - \\
\hline $\begin{array}{l}\text { Berries, } \\
\text { number }\end{array}$ & 429 & - & 798 & - \\
\hline $\begin{array}{l}\text { Berry average } \\
\text { weight, g }\end{array}$ & 2.26 & - & 1.22 & - \\
\hline Marc, g/kg & 189.84 & 18.98 & 238.45 & 23.85 \\
\hline
\end{tabular}


Table 2. Physico-chemical analyses of the must obtained from fresh grapes and from grapes naturally dried for 7 weeks (OIV methods and Glorie methodology).

\begin{tabular}{|l|c|c|c|}
\hline $\begin{array}{l}\text { Physico- } \\
\text { chemical } \\
\text { analyses }\end{array}$ & $\begin{array}{c}\text { Fresh } \\
\text { grapes } \\
\text { (harvesting } \\
\text { day, }\end{array}$ & $\begin{array}{c}\text { Raisins } \\
\text { (7 weeks } \\
\text { of drying, } \\
\text { until }\end{array}$ & $\begin{array}{c}\text { Ratio dried } \\
\text { grapes/ } \\
\text { fresh } \\
\text { grapes \% }\end{array}$ \\
\hline Brix, \% & 23.40 & 31.55 & 134.8 \\
\hline Sugar, g/l & 232.35 & 313.28 & 134.8 \\
\hline Density, g/cm ${ }^{3}$ & 1.0962 & 1.1364 & 103.7 \\
\hline $\begin{array}{l}\text { Total acidity, g/l } \\
\text { tartaric acid }\end{array}$ & 4.24 & 4.55 & 107.3 \\
\hline pH & 3.64 & 3.71 & 101.9 \\
\hline $\begin{array}{l}\text { Yeast assimilable } \\
\text { nitrogen (YAN), } \\
\text { mg/l }\end{array}$ & 40.10 & 174.43 & 435.0 \\
\hline $\begin{array}{l}\text { Total } \\
\text { anthocyanins } \\
\text { (ApH1), mg/kg }\end{array}$ & $\mathbf{2 0 6 9 . 8 3}$ & $\mathbf{2 5 4 4 . 9 2}$ & $\mathbf{1 2 3 . 0}$ \\
\hline $\begin{array}{l}\text { Extractable } \\
\text { anthocyanins } \\
\text { (ApH3.2), mg/kg }\end{array}$ & $\mathbf{8 3 1 . 2 5}$ & $\mathbf{1 1 0 8 . 7 0}$ & $\mathbf{1 3 3 . 4}$ \\
\hline $\left.\begin{array}{l}\text { Total polyphenol } \\
\text { index (TPI or } \\
\text { I }\end{array}\right)$, UA/kg & $\mathbf{3 8 . 2 0}$ & $\mathbf{4 8 . 0 4}$ & $\mathbf{1 2 5 . 8}$ \\
\hline $\begin{array}{l}\text { Anthocyanins } \\
\text { extractability } \\
\text { (AE), \% }\end{array}$ & $\mathbf{4 0 . 1 6}$ & $\mathbf{4 3 . 5 7}$ & $\mathbf{1 0 8 . 5}$ \\
\hline Seed tannins, \% & $\mathbf{1 2 . 9 7}$ & $\mathbf{7 . 6 9}$ & $\mathbf{5 9 . 3}$ \\
\hline
\end{tabular}

parameters are included in Table 3 and the parameters related to wine polyphenol compounds in Table 4.

As expected, there was a positive correlation between the alcoholic content of the wines and the sugar concentration in the raw materials (either fresh grapes or mash of wine with $50 \%$ of crushed dried grapes). A similar correlation, with a 0.75 correlation coefficient, was found by King et al. [21] in Malbec wines. However, in our case the correlation holds true only when we deduct form the initial sugar content the remnant sugar in the final wine, in which case the correlation coefficient is 0.83 (alcoholic content $\%(\mathrm{v} / \mathrm{v})=0.0608 \times$ transformed sugar concentration $\mathrm{g} / \mathrm{l})$. Whenever the dried grapes were used in winemaking, the yeasts were not able to ferment the wines to dryness, leaving about $20 \mathrm{~g} / \mathrm{l}$ unfermented sugar in DWDR and $102 \mathrm{~g} / \mathrm{l}$ in DR. Due to harsh conditions for the yeasts, the variant with $100 \%$ dried grapes (DR) actually yielded less alcohol than in the case of fresh grapes, fermentation stopping at $13.3 \%$ alcohol v/v.

The total and volatile acidity are increasing with the presence of dried grapes in the winemaking, from DW to DWDR to DR. However, the $\mathrm{pH}$ is increasing too, most likely due to a higher extraction of potassium from the dried grapes. The reduced dry extract is increasing as well from approximately $30 \mathrm{~g} / \mathrm{l}$ in DW, to $40 \mathrm{~g} / \mathrm{l}$ in DWDR and to $50 \mathrm{~g} / \mathrm{l}$ in DR.

One year after AF the volatile acidity slightly increased in all variants, while total acidity slightly decreased. The reduced extract, however, decreased in DW and DWDR variants, but not in DR, in which the natural stabilizing processes occurred with more difficulty, most likely due to the unusually high dry extract $(155 \mathrm{~g} / \mathrm{l})$.

For the results in Table 4, the T-test paired samples for $p<0.001$ shows that all the samples differed significantly at 14 months after AF as compared to the wines analyzed at 6 months, proving that the polyphenols evolved. In both stages of maturation ( 6 and 14 month after fermentation) all the parameters differed significantly for all the variants, most of them at the significance level $p<0.001$. Only at 6 months after AF the hue (DO420/DO520) and the difference in colour (\%dA) were not significantly different between DW, DWDR and DR, showing that the wines were still young and the maturation processes had not yet affected the colour and the overall hue was not influenced

Table 3. Dornfelder wine variants' main parameters determined in young wines and after 1 year from the alcoholic fermentation.

\begin{tabular}{|c|c|c|c|c|c|c|}
\hline \multirow{2}{*}{$\begin{array}{l}\text { Physico-chemical } \\
\text { parameters }\end{array}$} & \multicolumn{2}{|c|}{ DW (control) } & \multicolumn{2}{|c|}{$\begin{array}{c}\text { DWDR }(\mathbf{5 0 \%} \text { wine }+50 \% \\
\text { dried grapes })\end{array}$} & \multicolumn{2}{|c|}{ DR $(100 \%$ dried grapes $)$} \\
\hline & $\begin{array}{c}60 \text { days after } \\
\text { AF }\end{array}$ & $\begin{array}{c}1 \text { year } \\
\text { after } A F\end{array}$ & $\begin{array}{c}60 \text { days after } \\
\text { AF }\end{array}$ & $\begin{array}{c}1 \text { year } \\
\text { after } A F\end{array}$ & $\begin{array}{c}60 \text { days after } \\
\text { AF }\end{array}$ & $\begin{array}{c}1 \text { year } \\
\text { after } A F\end{array}$ \\
\hline $\begin{array}{l}\text { Alcoholic strength, } \\
\% \text { vol. }\end{array}$ & $13.68 \pm 0.07$ & $13.70 \pm 0.04$ & $15.29 \pm 0.02$ & $15.35 \pm 0.04$ & $13.27 \pm 0.03$ & $13.33 \pm 0.03$ \\
\hline $\begin{array}{l}\text { Volatile acidity, } \mathrm{g} / \mathrm{l} \\
\text { acetic acid }\end{array}$ & $0.27 \pm 0.00$ & $0.28 \pm 0.01$ & $0.68 \pm 0.02$ & $0.79 \pm 0.01$ & $0.91 \pm 0.01$ & $1.02 \pm 0.01$ \\
\hline $\begin{array}{l}\text { Total acidity, g/l } \\
\text { tartaric acid }\end{array}$ & $5.81 \pm 0.02$ & $5.75 \pm 0.01$ & $6.62 \pm 0.05$ & $5.91 \pm 0.01$ & $8.25 \pm 0.02$ & $8.19 \pm 0.02$ \\
\hline pH & $3.52 \pm 0.01$ & $3.50 \pm 0.02$ & $3.67 \pm 0.01$ & $3.73 \pm 0.00$ & $3.73 \pm 0.02$ & $3.69 \pm 0.02$ \\
\hline $\begin{array}{l}\text { Density at } 20^{\circ} \mathrm{C}, \mathrm{g} / \\
\mathrm{cm}^{3}\end{array}$ & $\begin{array}{c}0.99439 \pm \\
0.00002\end{array}$ & $\begin{array}{c}0.99443 \pm \\
0.00002\end{array}$ & $\begin{array}{l}1.00425 \pm \\
0.00006\end{array}$ & $\begin{array}{c}1.00443 \pm \\
0.00011\end{array}$ & $\begin{array}{l}1.04034 \pm \\
0.001\end{array}$ & $\begin{array}{l}1.03839 \pm \\
0.00002\end{array}$ \\
\hline Reducing sugars, g/l & $2.11 \pm 0.02$ & $2.75 \pm 0.12$ & $21.44 \pm 0.07$ & $19.72 \pm 0.25$ & $102.77 \pm 1.11$ & $102.15 \pm 0.27$ \\
\hline Total dry extract, $\mathrm{g} / \mathbf{l}$ & $34.34 \pm 0.21$ & $32.03 \pm 0.16$ & $66.39 \pm 0.15$ & $60.78 \pm 0.06$ & $154.75 \pm 1.56$ & $154.59 \pm 0.06$ \\
\hline Reduced extract, g/l & $32.23 \pm 0.19$ & $29.28 \pm 0.06$ & $44.95 \pm 0.21$ & $41.05 \pm 0.23$ & $51.98 \pm 0.71$ & $52.45 \pm 0.30$ \\
\hline
\end{tabular}


Table 4. Dornfelder wine variants parameters related to wine polyphenol compounds determined in wines after 6 months and 14 months from the alcoholic fermentation.

\begin{tabular}{|c|c|c|c|c|c|c|}
\hline \multirow{2}{*}{$\begin{array}{l}\text { Parameters related to wine } \\
\text { polyphenol compounds* }\end{array}$} & \multicolumn{2}{|c|}{ DW (control) } & \multicolumn{2}{|c|}{$\begin{array}{c}\text { DWDR (50\% wine }+\mathbf{5 0 \%} \\
\text { dried grapes) }\end{array}$} & \multicolumn{2}{|c|}{ DR (100\% dried grapes) } \\
\hline & $\begin{array}{l}6 \text { months } \\
\text { after AF }\end{array}$ & $\begin{array}{l}14 \text { months } \\
\text { after AF }\end{array}$ & $\begin{array}{l}6 \text { months } \\
\text { after AF }\end{array}$ & $\begin{array}{l}14 \text { months } \\
\text { after AF }\end{array}$ & $\begin{array}{l}6 \text { months } \\
\text { after AF }\end{array}$ & $\begin{array}{l}14 \text { months } \\
\text { after AF }\end{array}$ \\
\hline \multirow{2}{*}{ Color intensity (10 mm optical path) } & 25.911 & 24.233 & 40.485 & 38.012 & 70.918 & 69.029 \\
\hline & \pm 0.011 & \pm 0.018 & \pm 0.034 & \pm 0.018 & \pm 0.542 & \pm 0.452 \\
\hline \multirow{2}{*}{ Hue $\left(\mathrm{DO}_{420} / \mathrm{DO}_{520}\right)$} & 0.5288 & 0.5796 & 0.5506 & 0.5892 & 0.5339 & 0.6067 \\
\hline & \pm 0.000 & \pm 0.000 & \pm 0.001 & \pm 0.001 & \pm 0.021 & \pm 0.009 \\
\hline \multirow{2}{*}{$\% \mathrm{DO}_{420}$} & 29.82 & 31.53 & 30.46 & 31.66 & 29.65 & 31.98 \\
\hline & \pm 0.008 & \pm 0.013 & \pm 0.021 & \pm 0.018 & \pm 0.652 & \pm 0.254 \\
\hline \multirow{2}{*}{$\% \mathrm{DO}_{520}$} & 56.39 & 54.39 & 55.32 & 53.73 & 55.57 & 52.71 \\
\hline & \pm 0.009 & \pm 0.018 & \pm 0.026 & \pm 0.023 & \pm 0.975 & \pm 0.353 \\
\hline \multirow{2}{*}{$\% \mathrm{DO}_{620}$} & 13.79 & 14.08 & 14.23 & 14.61 & 14.78 & 15.31 \\
\hline & \pm 0.002 & \pm 0.005 & \pm 0.006 & \pm 0.006 & \pm 0.324 & \pm 0.101 \\
\hline \multirow{2}{*}{$\% \mathrm{dA}$} & 61.33 & 58.07 & 59.61 & 56.95 & 60.00 & 55.14 \\
\hline & \pm 0.015 & \pm 0.030 & \pm 0.042 & \pm 0.039 & \pm 1.572 & \pm 0.634 \\
\hline \multirow{2}{*}{ Monomeric anthocyanins, AU } & 8.93 & 6.99 & 11.74 & 7.62 & 21.48 & 13.27 \\
\hline & \pm 0.005 & \pm 0.026 & \pm 0.004 & \pm 0.032 & \pm 0.007 & \pm 0.017 \\
\hline \multirow{2}{*}{ Copigmented anthocyanins, $\mathrm{AU}$} & 2.79 & n.d & 1.50 & n.d & 2.10 & n.d \\
\hline & \pm 0.011 & - & \pm 0.032 & - & \pm 0.219 & - \\
\hline \multirow{2}{*}{ Polymeric anthocyanins, $\mathrm{AU}$} & 4.88 & 6.46 & 9.98 & 13.37 & 17.92 & 24.64 \\
\hline & \pm 0.001 & \pm 0.001 & \pm 0.001 & \pm 0.002 & \pm 0.006 & \pm 0.017 \\
\hline \multirow{2}{*}{ Colourless anthocyanins, AU } & 40.29 & 23.72 & 41.45 & 28.99 & 64.17 & 39.08 \\
\hline & \pm 0.087 & \pm 0.009 & \pm 0.051 & \pm 0.036 & \pm 0.209 & \pm 0.496 \\
\hline \multirow{2}{*}{ Total coloured anthocyanins, AU } & 16.60 & 13.21 & 23.22 & 20.62 & 41.50 & 36.05 \\
\hline & \pm 0.009 & \pm 0.007 & \pm 0.031 & \pm 0.019 & \pm 0.219 & \pm 0.505 \\
\hline \multirow{2}{*}{ Total anthocyanins, $\mathrm{AU}$} & 56.89 & 36.93 & 64.67 & 49.61 & 105.67 & 75.13 \\
\hline & \pm 0.090 & \pm 0.005 & \pm 0.040 & \pm 0.022 & \pm 0.070 & \pm 0.011 \\
\hline \multirow{2}{*}{ Total phenols, AU } & 79.56 & 74.51 & 114.12 & 99.72 & 190.78 & 176.89 \\
\hline & \pm 0.121 & \pm 0.053 & \pm 0.373 & \pm 0.172 & \pm 1.126 & \pm 1.339 \\
\hline \multirow{2}{*}{ Flavone cofactors, $\mathrm{AU}$} & 16.79 & 15.57 & 22.19 & 19.37 & 37.53 & 35.07 \\
\hline & \pm 0.010 & \pm 0.026 & \pm 0.008 & \pm 0.040 & \pm 0.011 & \pm 0.018 \\
\hline \multirow{2}{*}{ Aging index I } & 0.2938 & 0.4892 & 0.4297 & 0.6484 & 0.4319 & 0.6837 \\
\hline & \pm 0.0002 & \pm 0.0003 & \pm 0.0006 & \pm 0.0006 & \pm 0.0023 & \pm 0.0091 \\
\hline \multirow{2}{*}{ Aging index II } & 0.0857 & 0.1750 & 0.1543 & 0.2695 & 0.1696 & 0.3280 \\
\hline & \pm 0.0001 & \pm 0.0000 & \pm 0.0001 & \pm 0.0001 & \pm 0.0001 & \pm 0.0002 \\
\hline
\end{tabular}

*Wines buffered at $\mathrm{pH}=3.6$.

by the differences measured for monomeric and polymeric anthocyanins, total phenols or flavone cofactors, which are all positively correlated with the increase in the content of dried grapes used in winemaking. The colour impresses with its intensity, being in all cases above the usual values of 15-20 encountered for the red wines [22]. For the young dry Dornfelder wine (DW), the colour intensity, which is almost 26, is in agreement with previous studies when for the same type of wine in the same vineyards the intensity was 27.7 [8]. The other variants are however very intensely coloured, the IC values being 40.5 for DWDR and 70.9 for DR. These colour intensities are not lost during maturation, after 14 months from AF these being only slightly lower, 38 for DWDR and 69 for DR. The hue slightly evolved in time towards orange, but at these colour intensities the changes are not perceptible by the human eye. The monomeric anthocyanins decreased in the wines analyzed after 14 months from AF, by $22 \%$ in the case of DR and by 35-38\% in the case of wines with dried grapes. Accordingly, polymeric anthocyanins increased by 
Table 5. Sensory analysis of Dornfelder wine variants.

\begin{tabular}{|c|c|c|c|c|c|c|c|}
\hline \multirow{2}{*}{\multicolumn{2}{|c|}{ Sensory attribute* }} & \multicolumn{2}{|c|}{ DW } & \multicolumn{2}{|c|}{ DWDR } & \multicolumn{2}{|r|}{ DR } \\
\hline & & \multirow{2}{*}{$\begin{array}{l}\begin{array}{l}\text { Average } \\
\text { score }\end{array} \\
4 \\
\end{array}$} & \multirow{2}{*}{$\begin{array}{l}\text { Description } \\
\text { very good } \\
\end{array}$} & \multirow{2}{*}{$\begin{array}{l}\begin{array}{l}\text { Average } \\
\text { score }\end{array} \\
4 \\
\end{array}$} & \multirow{2}{*}{\begin{tabular}{|l|} 
Description \\
very good \\
\end{tabular}} & \multirow{2}{*}{$\begin{array}{l}\begin{array}{l}\text { Average } \\
\text { score }\end{array} \\
4 \\
\end{array}$} & \multirow{2}{*}{$\begin{array}{l}\text { Description } \\
\text { very good } \\
\end{array}$} \\
\hline Vicun & Limpidity & & & & & & \\
\hline visual & Aspect other than limpidity & 8 & very good & 10 & excellent & 10 & excellent \\
\hline \multirow{3}{*}{ Nose } & Nose Genuineness & 4 & good & 5 & very good & 5 & very good \\
\hline & Nose Positive intensity & 7 & very good & 7 & very good & 8 & excellent \\
\hline & Nose Quality & 12 & good & 16 & excellent & 14 & very good \\
\hline \multirow{4}{*}{ Taste } & Taste Genuineness & 5 & very good & 4 & good & 4 & good \\
\hline & Taste Positive intensity & 7 & very good & 7 & very good & 8 & excellent \\
\hline & Harmonious persistence & 7 & very good & 7 & very good & 8 & excellent \\
\hline & Taste Quality & 16 & good & 22 & excellent & 19 & very good \\
\hline \multirow[t]{2}{*}{ Harmony } & Overall judgement & 10 & very good & 10 & very good & 10 & very good \\
\hline & Total score & 80 & & 92 & & 90 & \\
\hline
\end{tabular}

*OIV unified card OIV UIO for wine contests.

$32 \%$ in DR and by 33 and $37 \%$ in DWDR and DR, respectively, the colour being stabilized in this way. Colourless anthocyanins also decreased in all variants. Overall, total anthocyanins decreased in 8 months of oxidative aging by $35,23,29 \%$, while total phenols decreased by $6,13,7 \%$ in DW, DWDR and DR, respectively. The aging indexes show the increasing contribution to wine colour during wine evolution. Aging index I (the spectral ratio of polymeric/total coloured anthocyanins) increased by 66,51 , $58 \%$ and aging index II (the spectral ratio of polymeric/ total anthocyanins) by $104,75,93 \%$ for DW, DWDR and DR, respectively.

It is worth reminding here that all the wine variants were supplemented from the beginning with a combination of ellagic, gallic and catechinic tannins, so that it would rapidly stabilize the colour and add aging potential to the wines, having known from previous studies in the same vineyard that in the Dornfelder, in spite of a high extract value and an anthocyanin content almost twice as much as in Cabernet Sauvignon, the tannins were only at concentrations closer to Merlot [8]. For the same reason, some producers choose to vinify the Dornfelder non-destemmed [23]. After studying 344 varieties Liang and his team [1] found no significant correlation between flavanols and anthocyanins, therefore, in some grape varieties, irrespective of how high the anthocyanin contents is, some tannin supplementation is necessary.

Polyphenols are important for the impression a wine makes, as regards to the bitterness and astringency, their combination in a particular wine defining the wine style. An application of sensomic on Amarone wine showed that the same active non-volatile compounds are found in both Dornfelder and Bordeaux wine and they are responsible for the taste impression [24], the style of each wine being defined by the quantities of these polyphenolic compounds.

\subsection{Wine sensory parameters and profile}

The bottled wines were sensorially assessed 14 months after the alcoholic fermentation was completed.
In order to rank the wines in accordance to their overall quality, the panelists blindly evaluated the wines by using the OIV unified card OIV UIO for wine contests. The average scores and the meaning of the values for each attribute are included in Table 5. It should be reminded that on this type of card, each attribute has a specific range, and the partial scores are not out of 10 , but are correlated with the importance of each parameter for the overall quality of a wine. However, when all the attributes are rated as "excellent" the total score is 100 . As it can be seen, the DWDR and DR ranked very close, with 92 and 90, respectively, in accordance with the wine contest regulations being entitled to a gold medal award. The classical dry wine (DW), however, was even below a silver medal score, in accordance with the wine contest rules silver medals starting from 82 . The DW received lower scores mainly for nose and taste quality, due to its lack of complexity.

Therefore, we have noted that it is for a reason that the varietal dry Dornfelder wines are rare in our climatic conditions and that these type of wines are used mainly to improve the colour of other wines, but not for personalized wines.

Table 6. Sensory evaluation of intensity perception of colour, aroma and of some main taste attributes for Dornfelder wine variants.

\begin{tabular}{|l|l|l|l|}
\hline \multirow{2}{*}{ Sensory attribute* } & \multicolumn{3}{|c|}{ Sensory perception average score } \\
\cline { 2 - 4 } & DW & DWDR & DR \\
\hline Acidity & 7.5 & 5 & 3.5 \\
\hline Sweetness & 0.5 & 2.5 & 5 \\
\hline Astringency & 4 & 5 & 6 \\
\hline Extract & 4 & 5 & 4.5 \\
\hline Colour intensity & 9.5 & 10 & 10 \\
\hline Aroma intensity & 5 & 7.5 & 8.5 \\
\hline
\end{tabular}

*Based on a score card for assessment of wine sensory perception of selected attributes [20]. 
To further characterize the 3 wine variants, the intensity perception of colour, aroma and of their main taste attributes were evaluated and the average results included in Table 6.

As expected, the wine obtained from raisins (DR) rated highest for sweetness and astringency, the determined sugar and total phenol increasing this way in the samples. However, the perception of extract was influenced by the overall equilibrium in taste, so that, in spite of the chemical parameter results, the perception for DR was a bit different, tasters scoring higher the DWDR sample. Very likely the lack of acidity in DR wine also influenced the perception of the mouthfeel attribute (extract).

Acidity perception rated high in the dry Dornfelder wine (DW), decreasing toward flatness in DR, although the chemical analyses show a totally opposed situation. The perception of acidity was very much influenced by the presence of sugar in DWDR wine $(20 \mathrm{~g} / 1$, half-sweet wine) and in DR wine (100 g/l, sweet wine). Actually, the acidity perception was strongly negatively correlated with the actual acidity in the sample $\left(\mathrm{R}^{2}=0.87\right)$ and with the $\mathrm{pH}$ $\left(\mathrm{R}^{2}=0.99\right)$, but highly positively correlated with the sugar content $\left(R^{2}=0.77\right)$.

The astringency was also highly positively correlated with the total phenol content $\left(\mathrm{R}^{2}=0.96\right)$ and with flavone cofactors content $\left(\mathrm{R}^{2}=0.92\right)$.

In some cases the sweetness perceived in the samples could also be correlated with the content of ethanol $\left(\mathrm{R}^{2}=0.60\right)$ and the $\mathrm{pH}\left(\mathrm{R}^{2}=0.43\right)$, as it was reported in a study for Malbec wines [King], but in our case this is not valid, as the DWDR and DR wines were not fermented to dryness.

The perceived colour intensity does not correlate anymore with any of the anthocyanin related parameters, as the high concentration even in the classic wine exceeded the power of discrimination of the human eye.

Table 7. Sensory evaluation of some main aroma attributes for Dornfelder wine variants.

\begin{tabular}{|l|l|l|l|}
\hline \multirow{2}{*}{\multicolumn{1}{|c|}{ Sensory attribute }} & \multicolumn{3}{c|}{ Sensory perception score } \\
\cline { 2 - 4 } & DW & DWDR & DR \\
\hline Vinosity & 5 & & \\
\hline Mineral, metallic, salty & 3 & & \\
\hline Vegetal, green pepper & 4 & 3 & \\
\hline Spicy & 2 & 5 & 6 \\
\hline Dates, figs, jam & & 6 & 3 \\
\hline Black currants & & & 5 \\
\hline Blueberries & 2 & & 8 \\
\hline Blackberries & & 7 & \\
\hline Cherry & & 7 & \\
\hline Bitter cherry & 3 & 8 & 2 \\
\hline Sour cherry & 5 & 3 & \\
\hline Raspberry & 2 & & \\
\hline Violets & 2 & 5 & 4.5 \\
\hline
\end{tabular}

*Based on a score card for assessment of wine sensory perception of selected attributes [20].
As it was also confirmed in the OIV scoring methods by the "nose positive intensity" attribute, here too the complexity of the DR wine was acknowledged by the highest score for "aroma intensity". In spite of its concentration in various aromatic compounds, due to the heavy concentration of sugar and low acidity the DR variant was not preferred by the tasters, who judged DWDR as being more balanced and pleasant.

In order to establish an aroma profile for the Dornfelder variants, aroma attributes were established by consensus and then the wines were blindly evaluated on 5 points discontinuous scales. The scales were marked from weak to strong, but no number anchored on them. Then points were awarded for each part of the scale, and the average results normalized to 10 and rounded to the nearest integer number. The results are presented in Table 7 and the aroma profiles derived from them in Figs. 2-4.

In accordance to the tasting scores and profiles the variants could be described as following:

- DW: is a simple wine, dissociated as regards to acidity, rather soft, lacking a certain structure in spite of the added tannin, with a certain opacity, sour cherry colour with a violet hue; the vinosity is predominant, with no particular aroma other than a dominant of sour cherry, with some vegetal notes and minerality. Normally the young Dornfelder wines are characterized by green vegetal notes, due to hexenal and hexanal [23] and these are found in our dry wine too.

- DWDR: is a complex and mellow wine, with a sweetness well balanced by the acidity, which feels like 8-10 g/l (while it is actually double); it is the longest, most persistent wine variant, very harmonious, dense, opaque, with a pure sour cherry colour (with no hue); it has intense, complex aroma, with a hint of diacetyl and a bit of ethanol and a dominant of sweet and bitter cherry, followed by ripen figs and dates, spices and violets. It is the most alcoholic of the wines and this influences too the aroma profile. As some authors pointed, red fruit aroma, associated with some monoterpenes, is better expressed in wines with higher amounts of ethanol $[21,25]$ and it seems to be valid for our samples too.

- DR: is a powerful wine, with tannin more present than in other variants, which confers structure without becoming unpleasant; dense in aspect, with pure sour

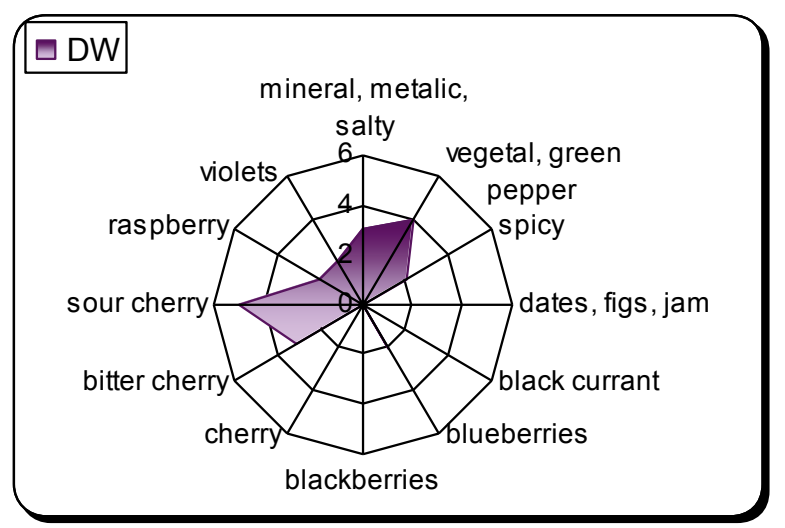

Figure 2. Aroma profile of dry Dorndfelder (DW) obtained by classical winemaking. 


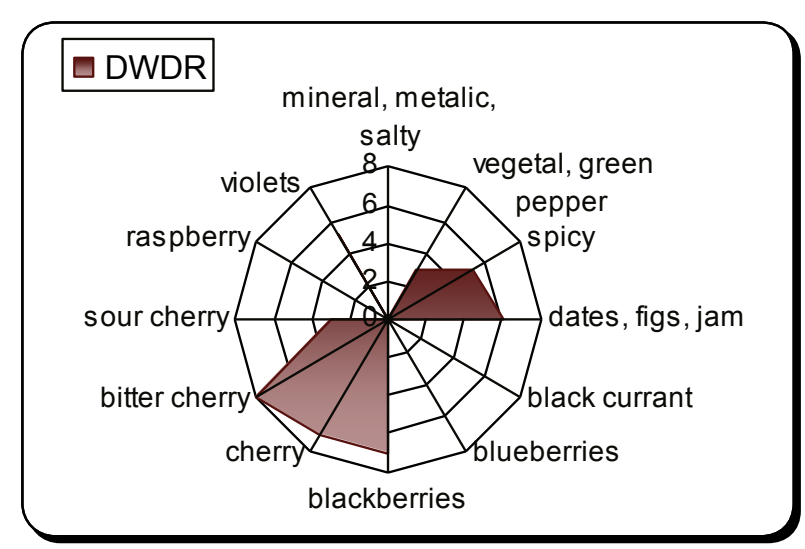

Figure 3. Aroma profile of half-sweet Dorndfelder (DWDR) obtained by fermentation of $50 \%$ DW and $50 \%$ raisins of Dornfelder grapes.

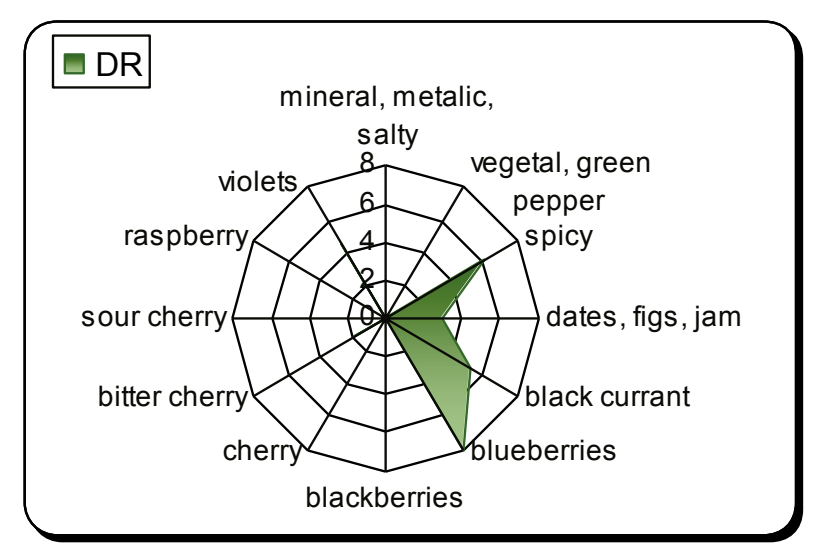

Figure 4. Aroma profile of sweet Dorndfelder (DR) obtained by fermentation of $100 \%$ raisins of Dornfelder grapes.

cherry colour (with no hue), more intense than DWDR, but less complex in fruity aroma, with a dominant of blueberry and back currant and some clove. The green vegetal notes characteristic to young Dornfelder wines are lost during grape drying, therefore are absent in DR and less intense in DWDR wines as compared to DW.

Hedonic tests performed with students in the campus and German wine college students visiting our university showed a preference for the DWDR.

\section{Conclusion}

The Dornfelder grape variety shows good prospects for Romania, where it maturates well and can even give typical varietal wines. Although the classical maturation-fermentation winemaking does not allow for the obtainment of complex and well-balanced wines, special technologies for wine production, using dehydrated Dornfelder grapes fermented in young Dornfelder wines can lead to particular wines, which can be consumed immediately after its production, but can also be kept for aging.
The process of drying Dornfelder grapes improves the phenol composition, but the wines produced only with the dried grapes are considered by most of the tasters too concentrated and sweet to be consumed as such. However, using the resulted raisins for a second fermentation in wine gives the final wine a more balanced sugar-acidity ratio, a round mouthfeel and a better perceived aromatic profile.

Although until now the Dornfelder was not very much used for varietal wines and is virtually unknown for the common Romanian consumer, the new style of wine proposed in this paper may help to slowly change this. It is our belief that due to its high yield, high anthocyanin content and overall quality, the surfaces with Dornfelder should be increased in Romania.

\section{References}

[1] Z. Liang, C.L. Owens, G.-Y. Zhong and L. Cheng, Polyphenolic profiles detected in the ripe berries of Vitis vinifera germplasm, Food Chemistry, 129, 940 950 (2011).

[2] International Organisation of Vine and Wine, International Code of Oenological Practices, SBN : 979-10-91799-35-5, Edition 2015, file:///C:/ Documents $\% 20$ and $\%$ osettings/Master/ Desktop/CODE_2015_EN.pdf

[3] Deutsches Weininstitut Gmbh, http://www. deutscheweine.de/wissen/rebsorten/ rote-rebsorten/dornfelder/

[4] Statistisches Bundesamt/Federal Statistical Office (Destatis); 31.07.2012, https://www.destatis.de

[5] Riesling and beyond in Germany: Masterclass, Wines of Germany, Guild of Sommeliers, July 2012, www.germanwineusa.com/.../pdf/ guild-germany-masterclass-7-12.pdf

[6] International Organisation of Vine and Wine, International list of vine varieties and their synonyms, Edition 2012, file:///C:/Documents $\div 20$ and $\% 20$ settings/Master/Desktop/ E_30_pays_compiled_EN.pdf

[7] A. O. Antoce, I. Nămoloşañu, D. Duşa, D. Mereanu, C. Rebigan, V. Nicolau, L. Călugăru, Some considerations regarding the grapevine variety assortment and wine categories in Romania in recent years", Bulletin de l'OIV, 86, ian-feb-mar 2013, No. 983-984-985, pp 27-45 (2013).

[8] A.O. Antoce, I. Nămoloşanu and A. Tudorache, "Sensory and composition profile of Dornfelder and Regent wines obtained in Romania", XXXIth World Congress of Vine and Wine (OIV), Verona, Italy, Congress Proceedings, DVD-ROM, 8 pages (2008).

[9] A. O. Antoce, Sensory evaluation of ripeness of Dornfelder and Regent grape varieties under the climatic conditions of south Romania, Lucrări ştiinţifice USAMVB, L, Seria B Horticultura, p. 435-439 (2007).

[10] E. Tosi, B. Fedrizzi, M. Azzolini, F. Finato., B. Simonato and G. Zapparoli., Effects of noble rot on must composition and aroma profile of Amarone wine produced by the traditional grape withering protocol, Food Chemistry, 130, 370-375 (2012). 
[11] Enologica Vason, Products, 2015, www.vason. com/eng/prodotti . php? sector=vason

[12] J. Blaha, On the uvological analysis of grapevine varieties, Vitis 4 (3) 233-239 (1964).

[13] International Organisation of Vine and Wine, Compendium of international methods of wine and must analysis, 1, ISBN Volume I: 979-10-91799-195, OIV-MA-INT-00-2014, Edition 2014 www. oiv. int/oiv/files/Compendium_2014_EN_ Volume1.pdf

[14] International Organisation of Vine and Wine, Compendium of international methods of wine and must analysis, 2, ISBN Volume II: 979-10-91799-20-1, OIV-MA-INT-00-2014, Edition 2014, www. oiv . int/oiv/files/Compendium_2014_EN_ Volume2.pdf

[15] Glories Y., La couleur des vins rouges. Les equilibres des anthocyanes et des tannins. Partie I. Connaissance de la Vigne et du Vin 18, 195-217 (1984a).

[16] Glories Y., La couleur des vins rouges. Mesure, origine et interprétation. Partie II. Connaissance de la Vigne et du Vin 18, 253-271 (1984b).

[17] T.C. Somers, M.E. Evans, Spectral evaluation of young red wines: Anthocyanin equilibria, total phenolics, free and molecular SO2, "chemical age." J. Sci. Food Agric. 28, 279-287 (1977).

[18] T. C Somers., G. Ziemelis, Interpretations of ultraviolet adsorption in white wines. Journal of the Science of Food and Agriculture, 23, 441-453 (1972).

[19] InternationalOrganisation of VineandWine, OIVstandard for international wine and spirituous beverages of vitivinicultural origin competitions, Resolution OIV/concours 332a/2009, www.oiv. int/oiv/ files / $3 \% 20$.../OIV-CONCOURS $20332 \mathrm{~A}-$ $2009 . p d f$ (2009).

[20] A. O. Antoce, I. C. Nămoloşanu, Method for sensory profile construction for defining and evaluating wine tipicality, Romanian Patent, Official Bulletin for Industrial Property BOPI nr 6/2007, patent 123129 issued on 30.11.2010.

[21] E.S. King, M. Stoumen, F. Buscema, A. K. Hjelmeland, Ebeler S.E., H. Heymann and Boulton R.B., Regional chemical and sensory characteristics of Malbec wines from Mendoza and California, Food Chemistry 143, 256-267 (2014).

[22] A.O. Antoce, Oenology. Chemistry and sensory analysis, Ed. Universitaria Craiova, in Romanian, (2007)

[23] S. Frank and P. Schieberle, Influence of the manufacturing process on changes on the concentrations of selected key aroma compounds of Dornfelder red wine, V. Ferreira and R. Lopez (Eds.), Flavour Science, Chapter 31, Elsevier, 525-529 (2014).

[24] N. Wollman, J.-C. Hunfnagel and T. Hofmann, Decoding the taste of red wine using a sensomic approach, V. Ferreira and R. Lopez (Eds.), Flavour Science, Chapter 97, Elsevier, 525-529 (2014).

[25] M.C. Goldner, M.C. Zamora, P. Di Leo Lira, H. Gianinoto and A. Bandoni, Effect of ethanol level in the perception of aroma attributes and the detection of volatile compounds in red wine, Journal of Sensory Studies, 24, 243-257 (2009). 